\title{
Review: Individual variability in feeding behaviour of domesticated ruminants
}

\author{
H. W. Neave, D. M. Weary and M. A. G. von Keyserlingk ${ }^{\dagger}$ \\ Animal Welfare Program, Faculty of Land and Food Systems, University of British Columbia, 2357 Main Mall, Vancouver, British Columbia, Canada V6T 124
}

(Received 1 January 2018; Accepted 17 April 2018; First published online 24 August 2018)

\begin{abstract}
Individual animals behave differently from one another, especially when confronting challenges such as changes in diet (e.g. weaning), environment (e.g. moving from pasture to feedlot) and social grouping (e.g. movement to lactating group after parturition). Each of these challenges involves some element of novelty, impacting the welfare and productivity of the animal. Indeed, the large individual variability in the development and expression of feeding behaviour cannot be fully explained by differences in genetics, management practices, body size or growth rate. In this review we outline evidence that individual variability in feeding behaviour is associated with the personality of the individual. We focus on three key personality traits: exploration, fear or reactivity and sociability. Individuals differ in how much they explore their feeding environment, with more exploratory individuals being less reactive to novel situations. Feeding behaviour can be impaired in individuals that are especially reactive to a change in their environment, change in diet or handling or restraint by humans. The social environment is also a major factor affecting how individuals express their behaviour. Sociability of the individual, including dominant-subordinate and affiliative relationships, affects how individuals make foraging decisions, gain access to feed and adopt particular social strategies to maintain or adjust feeding patterns when the social environment changes. Personality traits such as exploration, boldness and sociability also affect the use of social information when learning where, how or what to eat. Our review highlights the implications of feeding behaviour variability for the welfare and productivity of the individual, and how an understanding of personality can help tailor management to the needs of the individual.
\end{abstract}

Keywords: temperament, behaviour syndrome, coping style, individual differences, welfare

\section{Implications}

Individual animals respond differently to stressful events. Personality can influence how the animal responds to stressors, including those associated with the feeding environment. Understanding how personality traits affect feeding behaviour can help to create tailored management that better meets the needs of different individuals on the farm. Personality differences may affect, for example, diet choice in grazing systems, social dynamics in confined systems, and how well animals cope with the various dietary and environmental transitions common on many farms.

\section{Introduction}

Individuals vary in their feeding behaviour, including in the expression of distinct and consistent feeding patterns (e.g. Melin et al., 2005). These feeding patterns develop from an early age (Provenza and Balph, 1987), and are influenced

${ }^{\dagger}$ E-mail: nina@mail.ubc.ca by a number of management factors. For instance, the availability of preferred forages or habitats, the frequency of pasture rotation and the distribution and quality of forage sources influence the feeding behaviour of grazing herds (cattle: Launchbaugh and Howery, 2005; goats: Goetsch et al., 2010; sheep: Rutter, 2006). In confined systems, the timing and frequency of feed delivery, and feed bunk structure and space allowance, are important features of the feeding environment that affect the feeding behaviour of ruminants (cattle: von Keyserlingk and Weary, 2010; goats: Jørgensen et al., 2007). Domesticated ruminants are generally social so social interactions between group mates, including competition for resources and learning from social partners, can also affect feeding behaviour (Forbes and Kyriazakis, 1995; Proudfoot and Habing, 2015).

Farm animals often experience changes in nutritional, physical and social aspects of their feeding environment, such as diet, feeding space available for each individual and social regrouping changes. Individuals within a group may cope differently with these management changes. For 
instance, some individuals may fail or take longer to learn where, how or what to eat; whereas, others may be unable to cope within their social environment and thus fail to gain access to food resources. Both situations have the potential to result in animals that do not achieve their growth potential, perhaps due to inappropriate behavioural responses to the environment that may be accompanied by a pervasive negative emotional state such as frustration, anxiety or panic. Individuals that are more resilient when confronted with these management changes may be more likely to succeed on farms.

There is limited understanding of why individuals within a herd differ in their feeding behaviour, whether these differences are stable, and how these may vary in grazing $v$. confined systems. Knowing why characteristic feeding patterns develop and persist may help tailor management to the needs of the individual, especially given the development of technologies (e.g. precision nutrition) that allow for management at the individual rather than herd level. Behaviours that are consistent within individuals, but vary between individuals, are indicative of 'personality'. Specific aspects of the behavioural repertoire are referred to as personality 'traits', using terms such as fearful, aggressive and docile (for more details on this terminology refer to Carter et al., 2013). There is growing evidence that personality traits such as exploration, reactivity and sociability are associated with measures of growth and productivity in ruminants (Haskell et al., 2014). Individual variability in feeding behaviour, and the way in which individuals respond to their feeding environment may also be related to the personality of the individual.

The aim of this review is to critically examine the available literature describing individual variability in feeding behaviour of ruminants, and how this variability relates to personality traits in animals. We will focus especially on 'exploratory' and 'sociability' traits that have received limited attention compared with the more commonly cited 'fear' (Forkman et al., 2007) and 'reactivity' traits (Haskell et al., 2014). We first describe how variability in development and expression of feeding behaviour may contribute to differences in growth and productivity, and then describe how personality traits may play a role in how individuals interact with and respond to challenges faced in the feeding environment. Throughout we review evidence in both grazing (e.g. extensively raised on rangeland or intensively raised on pasture) and confined (e.g. raised indoors or finished on feedlots) systems.

\section{Individual variability in feeding behaviour}

\section{Development of feeding behaviour}

The young ruminant relies initially on milk and begins sampling solid feed within the first few weeks after birth (Nicol and Sharafeldin, 1975). The timing of the transition from nursing to a solid diet is highly variable among individuals; for example, natural weaning in domestic cattle was reported to be between 7 and 14 months after birth (Reinhardt and Reinhardt, 1981). Young ruminants will begin to graze by learning from social models such as the mother and conspecifics or learning by trial and error, leading to individual preferences and aversions to plants, and individual differences in ability to forage efficiently (Provenza and Balph, 1987; Kyriazakis et al., 1999). Even at an older age, social models may be useful when introducing naïve animals to new feeding systems; when dairy heifers were turned out to pasture for the first time without an experienced companion, some individuals took over $3 \mathrm{~h}$ to begin to graze compared with just $1 \mathrm{~h}$ for those that were pastured with an experienced grazer (Costa et al., 2016a).

In most dairy cattle production systems, calves are raised apart from their mother. Dairy farms vary in how much and how often milk is delivered to the calves and in opportunities for social learning (Vasseur et al., 2010; Hötzel et al., 2014; USDA, 2014); both factors may influence the development of feeding behaviours (reviewed by Miller-Cushon and DeVries, 2015). For example, calves reared individually must learn on their own where, how and what to eat. The lack of a social model may be particularly important during the transition from milk onto a solid diet, especially given that weaning occurs much earlier than in nature (Enríquez et al., 2011; reviewed by Khan et al., 2016).

Young ruminants vary in the amount of milk that they choose to consume when milk is provided ad libitum. This variability can contribute to differences in growth rates during the pre-weaning period. For example, de Passillé et al. (2016) reported a large range in milk intakes during the first 2 to 4 days of age in Holstein dairy calves, ranging from 2.4I to $12 \mathrm{l} /$ day (7 to $30 \%$ of BW), resulting in differences in BW gains (ranging from 0.07 to $1.2 \mathrm{~kg} /$ day in the first month of age). Similar variability in milk feeding patterns were reported for artificially-reared lambs, ranging from 0.3 to 2.9 l/day milk consumption (David et al., 2014).

Dairy calves raised indoors are typically introduced to a concentrate diet soon after birth. Considerable variability in concentrate consumption has been reported by several authors. Neave et al. (2018) showed that calves first found and began to consume grain at between 4 to 41 days of age when fed either $6,8,10$ or $12 \mathrm{l} /$ day of milk. Calves fed $12 \mathrm{l} /$ day of milk first consumed $200 \mathrm{~g} /$ day of grain at between 23 to 82 days of age and first reached a daily grain consumption of $1400 \mathrm{~g} /$ day at between 58 to 94 days of age (de Passillé and Rushen, 2016). Calves fed less milk typically begin to consume more grain at an earlier age; however, Roth et al. (2009) showed that even when calves were fed just $6 \mathrm{I}$ of milk/day, the age range when they first consumed $2000 \mathrm{~g} /$ day of grain was between 45 and 98 days of age. Furthermore, when group-housed calves were offered free choice of milk replacer, concentrate, maize silage, hay and straw, there was large individual variability in intake of each component, suggesting that calves develop diet preferences from a young age (Webb et al., 2014). These preferences may also arise from associations between sensory properties and nutritional value of the diet (Forbes and Kyriazakis, 1995), the experiences associated with the first encounter 
with the feedstuff, or the physical properties of the diet that are important for stimulating ruminal development (Baumont, 1996).

This evidence highlights the variation in feeding behaviour among individuals from a young age. It is well known that reduced milk intake or reluctance to transition to solid feed can result in impaired growth during the pre-weaning and weaning periods in young ruminants (e.g. dairy calves: de Passillé et al., 2016; goat kids: Warmington and Kirton, 1990; lambs: Greenwood et al., 1998). Furthermore, earlylife nutritional disadvantages have been shown to affect future foraging behaviour in other species (e.g. Andrews et al., 2015). Understanding how and why some individuals develop feeding patterns that result in better or worse performance is important if we are to help all animals thrive.

\section{Expression of feeding behaviour}

Characteristic feeding patterns that develop from an early age in ruminants appear to also be present in adulthood. The rearing environment, as well as morphological and physiological differences, will have a profound impact on how individuals express their feeding preferences and patterns as adults (Provenza and Balph, 1987). Individuals within a herd can show feeding patterns that are widely variable between individuals but remain relatively consistent over time within individuals (Melin et al., 2005). This is not to say that feeding behaviour is inflexible, but rather that the degree of flexibility in feeding patterns generally remains consistent within individuals over time.

The selection of, and preference for, plants to graze or browse will depend on the individual's nutritional needs and on prior experience with these food sources and ability to cope with toxins (Provenza et al., 2003). Ruminants are known to make trade-offs in selecting diets that meet the requirements of their internal state (e.g. hunger, and physiological state such as pregnancy) while reducing costs in the selection of the diet (e.g. environmental or social pressures) (Kyriazakis et al., 1999; Arsenos et al., 2000). Thus an individual's diet selection is flexible with changing internal state, with changes in diet dependent upon any nutritional deficiency and post-ingestive feedback from ingested foods (e.g. Tolkamp et al., 1998). Day et al. (1998) proposed that food selection is also influenced by a motivation to explore the feeding environment, which functions to identify new food items and to monitor and update information on existing food sources; individuals are able to modify their feeding behaviour if needed.

Foraging animals must choose between continuing to exploit an existing site or searching for a superior foraging site (see Giraldeau and Caraco, 2000). One approach to understanding this dichotomy is the producer-scrounger model, originally developed to describe the feeding strategies of sparrows (Barnard and Sibly, 1981). 'Producers' take the role of finding higher food quality food patches. These individuals benefit from first access to the new patch, but pay the cost of lost foraging opportunities (and perhaps increased predation) while searching for new patches (Giraldeau and
Caraco, 2000). Other individuals adopt a 'scrounger' strategy of following 'producers' to exploit their findings rather than searching for food themselves. This framework has been applied to foraging strategies in goats (Stears et al., 2014) and sheep (Hewitson, 2002). Individuals within a herd may also adopt 'leader' and 'follower' roles in making decisions when to move between feeding locations including cattle (Dumont et al., 2005), sheep (Squires and Daws, 1975), goats (Escós et al., 1993) and buffalo (Prins, 1996). 'Producers' may be more likely to be 'leaders' but this line of research has yet to be explored.

Given the evidence of individual variability in diet selection of foraging animals (Kyriazakis et al., 1999; Arsenos et al., 2000), it follows that there would be similar variability in the feeding patterns of confined ruminants. For instance, Melin et al. (2005) found that as much as $84 \%$ to $98 \%$ of the variation in feeding patterns could be attributed to individual differences between dairy cows. Several studies have shown substantial between-cow variability for meal frequency (e.g. ranging from 5 to 9 meals/day) and feeding time (dairy cattle: 250 to $450 \mathrm{~min} /$ day; beef cattle: 8 to $90 \mathrm{~min} /$ day or 86 to $120 \mathrm{~min} /$ day) (Schwartzkopf-Genswein et al., 2002; DeVries et al., 2003). Such feeding patterns have been attributed more to phenotypic than to genetic variation among individuals (Løvendahl and Munksgaard, 2016).

Studies have also shown that some individuals will adjust their feeding behaviour in response to social or environmental changes. Crossley et al. (2017) reported that when dairy cows competed for access to a feeding area, there was an increase in variability in feeding time, feeding rate and meal duration. In a companion study, increasing feeding frequency did not reduce variability in feeding time, feeding rate or dry matter intake (Crossley et al., 2018). This variability is likely due to individual motivations to access the feed bunk; some animals reduce feeding time and others strive to maintain feeding times even under high levels of competition (dairy cattle: Val-Laillet et al., 2008b; goats: Jørgensen et al., 2007). Some individuals will also respond more negatively than others when experiencing environmental changes. For instance, Rice et al. (2016a) found that $18 \%$ of lambs entering a feedlot spent less than $30 \mathrm{~min} /$ day feeding, lost weight during the $1^{\text {st }}$ week, and were more likely to visit the feeder when no other lambs were present. This evidence suggests that the feeding behaviour of some individuals will change in response to social or environmental pressure.

In summary, there is wide individual variability in feeding behaviour from an early age. Understanding why feeding behaviour is variable among individuals will be the focus of the remainder of this review, particularly how personality traits such as exploration, fear or reactivity and sociability affect how ruminants interact with their feeding environment.

\section{Exploring the feeding environment}

\section{Foraging strategies}

Studies on the personality characteristics of individuals adopting producer-scrounger or leader-follower foraging 
strategies often profile animals along an explorationavoidance or boldness-shyness axis, and individuals that are more exploratory or bold are thought to be more likely be leaders or producers by searching for food rather than relying on others (Kurvers et al., 2012). For example, sheep that were more exploratory in an unfamiliar arena with novel objects were also more likely to move away from conspecifics while grazing, enabling them to explore more of the pasture area (Sibbald et al., 2009). Sheep that were more exploratory were also more likely to split into smaller subgroups, indicating these animals made the trade-off to explore their feeding environment rather than to remain together as a cohesive group (Michelena et al., 2009). Domestic deer that spent more time close to or investigating novel objects made a similar trade-off, spending less time engaged in vigilant behaviours and more time investigating a novel food (Bergvall et al., 2011). In addition, beef heifers that spent more time interacting with a novel object tended to be positioned at the front of the herd (Ramseyer et al., 2009). These studies suggest that more exploratory individuals (as indicated by greater investigation of novel objects or food) adopt riskier foraging behaviour and that this results in increased opportunities to forage.

In confined farming systems, ruminants are typically provided uniform diets at specific times of the day, reducing the need for deciding when and where to forage. Indoor-housed animals will still perform exploratory behaviour, particularly when the feed quality is variable (Huzzey et al., 2013). Meagher et al. (2017) offered feed bins with different forage varieties or flavours along a feed bunk and recorded the number of bin switches as a measure of exploratory feed sampling. Heifers that spent more time in contact with a novel object in a previous test also spent more time exploring and eating the varied feed. Moreover, those that were quicker to reach a novel food in the individual test also spent more time at the varied feed and switched between bins more often. Most recently, dairy calves that were most exploratory in a novel environment began to eat grain earlier, consumed more grain and gained more weight (Neave et al., 2018). Collectively this evidence indicates that some individuals are more proficient in exploring and sampling varied or novel feeds.

\section{Feed sampling and sorting behaviour}

Dairy cows are known to preferentially sort for concentrate and against long forage components in a mixed ration but this type of behaviour is highly variable among individuals, with some even sorting against the typically preferred finer particles (Leonardi and Armentano, 2003). Interestingly, sorting behaviour did not decrease when cows were fed in a competitive feeding environment (Hosseinkhani et al., 2008), suggesting that individuals engaging in this behaviour are motivated to do so even when access to feed is limited. A possible explanation for this finding is that individuals that continued to sort in a competitive environment were also higher in social rank and thus could maintain their position at the feed bunk (see Favati et al., 2014).
Sorting is also likely a learned behaviour, related to postingestive feedback mechanisms (Provenza, 1995), and familiarity of feed from an early age (Miller-Cushon and DeVries, 2011). Consequently, young dairy calves are able to sort a mixed ration and will adjust this behaviour in response to the availability of grain (Costa et al., 2016b). Feed sorting is seen as a risk factor for ruminal acidosis in adult cows (Cook et al., 2004), so farms often strive to prevent this type of behaviour. If indeed the motivation behind sorting behaviour stems from a desire to explore the feeding environment, management practices may be able to redirect this behaviour by offering other opportunities for environmental exploration or manipulation. To our knowledge, no work to date has explored such opportunities.

Overall, individuals differ in how much they explore their feeding environment. Some individuals are producers or scroungers, and some are leaders or followers when it comes to deciding how and where to find food. In confined housing, these foraging differences have yet to be documented, but individuals that sample their feeding environment have been shown to be more exploratory and bold in novel situations. Individuals that are more reactive in response to novelty (rather than exploratory or bold) also show differences in their feeding behaviour; this will be the focus of the next section.

\section{Coping with stress: response patterns and fearfulness}

Domestic ruminants experience many stressors; differences in the behavioural responses of individuals toward these stressors are called 'coping styles' (Benus et al., 1991; Koolhaas et al., 1999). Individuals also differ in their level of fear when responding to a stressful event, where more fearful individuals typically show stronger behavioural responses (e.g. Boissy, 1995). The quality (i.e. coping style) and magnitude or quantity of the response (i.e. fearfulness) may reflect two independent dimensions that together describe how individuals respond to a particular stressor (Koolhaas et al., 2007). This framework is supported by the multivariate analysis of the behavioural responses of dairy heifers exposed to different stressors including a novel environment, stationary human, novel object and restraint (Van Reenen et al., 2002, 2005).

For some individuals, adjustments to their feeding behaviour may be a coping mechanism in response to changes in the feeding environment or other stressors. There is growing evidence in ruminants that feeding behaviour, including feed intake, may be reduced when individuals that are particularly fearful experience stressful events such as changes in the environment or feed type, or handling and restraint by humans. We will review this evidence in the next sections.

\section{Reactivity to novel environments}

Dairy heifers are known to differ in their responses when first introduced to the milking parlour; Van Reenen et al. (2002) showed that some individuals had consistently higher physiological (i.e. cortisol) and behavioural reactivity (i.e. 
stepping and kicking) during milking preparation and teat cup attachment. Heifers habituated to the milking parlour for several weeks before calving had improved feed intake compared with those that were not habituated (Daniels et al., 2007). Thus changes in feeding behaviour may be an indication of individuals that are especially affected by novel processes like milking.

Several authors have reported individual variability in physiological stress responses in cattle (e.g. Loerch and Fluharty, 1999; Eitam et al., 2010) and lambs (Rice et al., 2016b) when introduced to a feedlot. Lambs with a high cortisol response during the $1^{\text {st }}$ week in this new environment were also more reactive during isolation and restraint tests and had a greater number of feeding bouts likely due to a high number of displacements.

Some personality traits may drive consistent behavioural responses across a range of situations, whereas other traits may only manifest under specific contexts (Sloan Wilson et al., 1994; Beausoleil et al., 2012). For instance, lambs that spent $<30 \mathrm{~min} /$ day feeding in the $1^{\text {st }}$ week after arriving at the feedlot (termed 'shy-feeders') had no relationship with behavioural responses during isolation and restraint (Rice et al., 2016a). However, this study used a standardized test that elicited a fear response specific to isolation which may be unrelated to responses to stressors encountered in a highly social feeding environment. Future work should aim to identify personality traits that are specific to individuals that show changes in their feeding behaviour when introduced to new environments and how modifications to that environment may be beneficial.

\section{Food neophobia}

Food neophobia, defined as a reluctance to eat unfamiliar foods (Chapple and Lynch, 1986), is well-known in ruminants and is thought to help animals avoid toxic plants (Provenza and Balph, 1987). This fear of novel diets must be overcome for livestock to transition to different feed types (Launchbaugh et al., 1997). When this transition is coupled with a change in environment, food neophobia is greater compared with when animals remain in familiar environments (Burritt and Provenza, 1997). Individuals will even consume familiar foods containing toxins over novel feeds when in an unfamiliar environment (Burritt and Provenza, 1997). However, early exposure to a diversity of foods can increase acceptance of novel foods especially in unfamiliar locations (Villalba et al., 2012).

Variability in feeding behaviour may be due in part to differences in food neophobia. For instance, Rice et al. (2016a) suggested that highly reduced feeding times in some lambs ('shy-feeders') may be due to individual differences in food neophobia. This reluctance to sample novel feeds can be consistent over time and in different contexts. For example, Costa et al. (2014) demonstrated that dairy calves were consistent across days in their willingness to sample two types of novel foods (carrots and hay), and heifers that were quick to find and eat more of a novel food in an arena also spent more time eating flavoured and varied forages offered at the feed bunk (Meagher et al., 2017). In lambs, individuals that were more food neophobic were also more fearful in a novel arena and exhibited more stress-induced hyperthermia (Villalba et al., 2009), suggesting that the test of food neophobia reflects fearfulness. These experimental findings were recently supported in a study of pair-housed calves on a commercial farm that consumed nearly three times as much novel food compared with isolated calves (Whalin et al., 2018). No studies have investigated how food neophobia is related to other personality traits, such as exploration and sociability.

\section{Reactivity to handling}

Individuals differ in their reactivity to handling and restraint. Many such interactions occur in farm animal production including vaccinations, dehorning, branding or castrating. With the advances of automated management technologies, opportunities for positive interactions and habituation to humans may be limited (Rushen et al., 1999; Butler et al., 2012). Poor handling and fear of humans are expected to alter the behaviour of the animals, including changes in feeding behaviour. For instance, beef cattle that are especially reactive when in the chute or isolated in a pen with a handler (i.e. nervous, vigorous or violent movement, or attempts to escape), and have high flight speeds exiting the chute, also have reduced feed intake (Black et al., 2013; Llonch et al., 2018), reduced feeding times (Cafe et al., 2011) and increased feeding bouts of shorter duration (Llonch et al., 2018). Similar effects on feeding behaviour have been shown in physiologically more reactive cattle (e.g. high cortisol response when in the chute; Llonch et al., 2016). However, other studies have not found a relationship between reactivity and feed intake (Petherick et al., 2002; Francisco et al., 2015) or feeding time (Nkrumah et al., 2007). These inconsistent results may be related to how personality measures were analysed (e.g. categorical, such as 'adequate' $v$. 'excitable' in Francisco et al., 2015, or continuous, such as scoring personality from 1 to 5 in Cafe et al., 2011) or may be related to the degree of negative experiences associated with humans (e.g. blood samples were taken before personality measures were scored in the chute; Cafe et al., 2011).

Apart from feed intake and feeding time, no studies have examined how reactivity to handling influences other aspects of feeding behaviour in ruminants. However, work on other farm animals shows an association. For example, reactivity during weighing was associated with more visits to the feeder and less intake per visit in pigs (Ros-Freixedes et al., 2014). Rohrer et al. (2013) found that pigs that struggled more during restraint in the supine position (i.e. 'reactive' pigs) tended to have fewer daily meals and these were of longer duration compared with 'proactive' pigs. 'Reactive' pigs also preferred to eat at times when the feeder was less occupied. These studies suggest that active movement during restraint may be related to active avoidance of social conflict at the feeder.

Stress from prolonged or repeated unpleasant handling can lead to impaired growth and productivity (e.g. Lensink 
et al., 2000). Whether growth is reduced due to changes in feeding behaviour that limit feed intake, or due to poorer feed efficiency, remains unknown. Recent research has shown that human presence can have a profound impact on goat behaviour; even changes in a human's head position can alter the behaviour of goats (Nawroth et al., 2015). Thus, the behaviour of stockpersons during management practices may elicit stress responses that in turn affect feeding behaviour. Together this evidence suggests that reactive individuals may be more prone to changes in feeding behaviour.

In summary, individuals differ in the way they respond to stressful events on farms. Feeding behaviour and feed intake can be impaired in individuals that are particularly reactive to a change in environment (feedlot, milking parlour), change in diet (food neophobia) and handling by humans (e.g. restraint in a chute). Aspects of the social environment may also be stressful for some individuals, and the way in which individuals respond to stressors may be related to the social relationships within the herd. We turn to this topic in the following section.

\section{Social relationships}

Most farm animals are housed in groups, resulting in a feeding environment that also involves interactions with other individuals. This can be a source of stress for some individuals, especially when the number of animals exceeds resource availability and results in competition for food (Proudfoot and Habing, 2015). The social context, including social relationships among individuals, has a major effect on behaviour. These social relationships can be agonistic (e.g. dominant-subordinate) or affiliative (e.g. sociability).

\section{Dominant-subordinate relationships}

Domestic ruminants are gregarious and will organize themselves into social hierarchies with dominant and subordinate individuals (e.g. cattle: Bouissou et al., 2001; goats: Miranda-de la Lama and Mattiello, 2010). An individual's position in the hierarchy is often expressed through agonistic interactions when gaining or maintaining access to resources (Miller and Wood-Gush, 1991; Barroso et al., 2000). For grazing ruminants on rangeland, where space is less limited, this hierarchy is related to priority of access to high-quality grazing areas (Barroso et al., 2000), which can be expressed as an 'avoidance order' whereby, subordinate animals avoid conflict with dominant ones (Sárová et al., 2010).

Feeding behaviour is related to the social rank of the individual with dominant individuals typically having priority access to food. This is especially evident when forage is limited and low in quality. For example, higher-ranking goats will out-compete subordinates to consume preferred shrubs (Barroso et al., 2000) and dominant individuals are often more efficient foragers (e.g. Thouless, 1990), likely due to less selection required when given priority access to feed resources. To achieve these foraging advantages, dominant animals position themselves toward the front of the herd and cover shorter distances relative to subordinates during periods of foraging (Sárová et al., 2010). Consequently, subordinates are often forced to graze areas of lower quality; these individuals could move away from the group in search of improved grazing opportunity but risk increased exposure to predators (Thouless, 1990; Barroso et al., 2000). Indeed, the slower bite rate of subordinates is thought to reflect the trade-off between grazing and maintaining vigilance for predators and dominant animals, in addition to the increased necessity to select forage (Thouless, 1990). Interestingly, subordinates also reduce bite rate when dominant individuals are nearby, and cease grazing altogether to avoid neighbouring dominant animals (Thouless, 1990). Together this evidence indicates that dominant-subordinate relationships are important drivers of foraging behaviour in grazing systems.

Dominant-subordinate relationships in confined housing systems also influence feeding behaviour. Subordinate individuals may fail to gain access to the feed bunk and eat at times that are less preferred (Huzzey et al., 2006), and even sacrifice higher quality feed to avoid feeding near a dominant (Rioja-Lang et al., 2009). These effects may be exacerbated when competition for feed increases (e.g. Jørgensen et al., 2007). Although dominance rank is often scored as the number and outcome of agonistic interactions between dyads (Galindo and Broom, 2000), displacements at the feeder by cattle has been reported to be bi- or tri-directional and nonlinear with subordinate cows occasionally displacing dominants (Val-Laillet et al., 2008a). Of most interest is that high-ranking cows do not necessarily have the longest feeding times; dominance at the feed bunk may be related to individual motivation to gain access to feed or to defending the resource (Val-Laillet et al., 2008a; b).

Variability in social behaviour at the feeder cannot be explained entirely by dominance. For example, Miranda-de la Lama et al. (2011) described four social strategies or 'identity profiles' in goats: 'passive' goats (submissive but made no attempt to avoid or engage in agonistic behaviour) spent the least time at the feeder, whereas 'avoider' goats (submissive and avoided both agonistic and even nonagonistic behaviour) spent the most time feeding. Goats that were 'aggressive' (highly dominant and mediated other social conflicts) and 'affiliative' (average dominance and engaged in socio-positive behaviours) were similar in time spent at the feeder but intermediate to 'avoider' and 'passive' goats. Thus individuals can share similar dominance ranks yet adopt different social strategies that impact feeding behaviour.

Temporal feeding patterns and other measures of feeding behaviour such as feeding rate can further our understanding of how individuals are able to maintain or adjust feeding time under competitive conditions when adopting different social strategies. Zobel et al. (2011) noted that beef heifers varied in how they responded to a highly competitive feeding environment; some individuals actively engaged in competition while maintaining a relatively stable feeding rate, but others appeared to actively avoid competition and shifted their feeding until after peak feeding time. Still, others 
appeared to adopt a 'get-in-and-get-out' strategy characterized by increased feeding rate and avoidance of agonistic interactions. Indeed, Nielsen (1999) noted that changes in feeding rate could be a valuable indicator of social pressure experienced by individuals in group feeding environments.

These results suggest avenues for future research. Given that individuals differ in their responsiveness to environmental change (i.e. behavioural plasticity; reviewed in Dingemanse et al., 2010), we might expect that some individuals will adjust their social behaviour at the feed bunk in response to a change in social environment (e.g. reduce aggression when there is low stocking density or when there are many other dominant individuals), whereas others will remain consistent across different social environments (e.g. maintain aggression despite plenty of space to access feed). This research would help to advance our understanding of, and opportunities for management of, the social grouping of ruminants in both grazing and confined feeding environments.

\section{Affiliative relationships and sociability}

Herd-living animals also have affiliative relationships, and these are also likely to influence social behaviour in the feeding environment. The formation of affiliative relationships among individuals has been reported among domestic ruminants, including cattle (Bouissou et al., 2001), goats (Miranda-de la Lama and Mattiello, 2010) and sheep (Lynch et al., 1992). Dairy cows form and maintain preferred partnerships from an early age (Raussi et al., 2010) with large within- and between-cow variability in the frequency of social interactions and time spent in close proximity to partners (Gutmann et al., 2015). This variability in sociability has been proposed as a distinct personality trait underlying how individuals respond to environmental challenges (Koolhaas and Van Reenen, 2016). Sociability can be defined as the motivation to remain close to conspecifics (Sibbald et al., 2005), and appears to be linked with feeding patterns of grazing animals that must make trade-offs between social and feeding motivations. For example, when high-quality forage is distributed in patches, the intake and diet composition of each individual depends on their willingness to move away from the herd to graze preferred patches (Sibbald and Hooper, 2003). In a subsequent paper, these authors (Sibbald and Hooper, 2004) demonstrated that more sociable sheep (i.e. those that spent the most time in close proximity to other sheep) were less likely to move away from the group to access a preferred grazing patch.

These foraging trade-offs appear to be influenced by the strength of relationships with herd mates. Dumont and Boissy (2000) reported that ewes penned with familiar companions chose to graze away from the group for longer periods, vocalized less and were less vigilant than those grazing with unfamiliar companions. Brahman steers were also more willing to leave a familiar companion to approach a food bowl but did not do so when housed with an unfamiliar companion (Patison et al., 2010). These authors suggested that a combination of a lack of social support and fear of isolation motivated individuals to remain close to unfamiliar companions. Sociability is also related to group movements between foraging sites. Ramseyer et al. (2009) demonstrated that heifers with limited affiliative partnerships and ewes that often grazed away from the group were those that most often initiated group movement.

In confined housing systems there is also evidence that individual differences in sociability influence feeding behaviour. Gibbons et al. (2010) found that dairy cows who took longer to return to the group following separation at the end of a passageway had more limited partner associations, were less synchronized with the group, and did not feed during peak feeding times. The strength and type of partner associations appears to affect feeding behaviour. Individuals housed together for longer periods were more likely to be preferential partners during feeding (dairy cattle: Gutmann et al., 2015; goats: Aschwanden et al., 2008), and these feeding partners showed more positive social contact such as allogrooming (Val-Laillet et al., 2008a). These studies suggest that preferential associations among individuals can influence feeding behaviour in both grazing and confined herds. Future research should aim to understand how the quality and quantity of relationships between individuals influences how individuals make foraging decisions and affect feeding patterns. For instance, individuals that develop close social bonds may become more reliant on a social partner to find high-quality food in a grazing system. Furthermore, individuals with strong social bonds or many social partnerships may be better able to cope with stressful feeding environments given that social partners often mediate stress responses in farm animals (Rault et al., 2011).

\section{Social facilitation and social learning}

Social companions are important sources of information for making foraging decisions in both grazing and confined housing systems. Social facilitation and social learning play important roles in the development of foraging behaviour in neonatal ruminants on pasture (Launchbaugh and Howery, 2005). Social facilitation is the phenomenon where the stimulus of another animal eating, approaching or manipulating feed may increase attention toward the feed, and subsequently encourage consumption of feed by others, whereas social learning describes the mechanism of learning through observation of others (Zentall and Galef, 1988).

Young ruminants learn from their mother and conspecifics the location of food, water and shelter, and consequently develop diet and habitat use patterns that resemble those of social models (Provenza and Balph, 1987). For instance, individuals that were conditioned to avoid a particular plant when grazing alone began to consume this plant when grazing with others that had not learned to avoid this plant (cattle: Ralphs et al., 1994; lambs: Provenza and Burritt, 1991). Social models can be influential in learning how to graze; naïve beef calves had increased grazing activity when turned out to pasture with experienced companions compared with those without an experienced social model (Hessle, 2009). 
For young ruminants that are raised in confinement, social facilitation and social learning may influence how quickly individuals begin to use feeding equipment. Lambs were quicker to learn to drink milk from a teat when grouped with lambs that had previously learned this behaviour (Veissier and Stefanova, 1993). Dairy calves raised with a social partner consumed more starter during the milk feeding period (Costa et al., 2015), were quicker to first visit a new concentrate feeder when regrouped after weaning (de Paula Vieira et al., 2010) and had more frequent concentrate meals before and during weaning (Miller-Cushon and DeVries, 2016) compared with calves raised alone. Consequently, socially housed calves have improved feed intake and weight gains (reviewed by Costa et al., 2016c). Together the evidence in both grazed and housed ruminant species suggests that learning about the feeding environment is influenced by the presence of social models.

Social foraging theory suggests that obtaining information by observing others is less costly than gaining the same information personally (Galef and Laland, 2005). An exciting area of research is how individuals differ in their use of social information, such that some may be more likely to learn from social information in a feeding context. Sih and Bell (2008) suggest that more sociable individuals may be more likely to acquire social information, given their close proximity and increased interactions among group mates compared with less sociable individuals. Indeed, the development and extent of social relationships among individuals in a grazing herd of cattle have been shown to be critical in the efficiency of information transfer (Launchbaugh and Howery, 2005). Similarly, the development of solid feeding behaviour in young ruminants requiring the discovery and exploitation of a novel food resource may be influenced by the sociability of the animal such that strong affiliations may lead to increased attention to social cues. Naïve observers may pay more attention to experienced demonstrators if they share a particular relationship (see review by Nicol, 1995).

The personality of the demonstrator may also suggest to observers within the herd that they are a reliable source of information. For instance, observers may watch and learn from the foraging behaviour of more exploratory or dominant individuals (Nicol, 1995). Indeed, there is evidence suggesting that the feeding behaviour of dominant individuals is copied by subordinates (Laland, 2004). This line of research has been tested in some ruminants. In sheep, dominance status of both the observer and demonstrator affected decisions to leave a food patch for a potentially better foraging opportunity (Hewitson et al., 2007); subordinate sheep would only follow a dominant when the expectation for discovering high-quality food was high. In contrast, Baciadonna et al. (2013) found that the use of social information by goats to locate a food patch was not dependent upon the dominance rank of the demonstrator. However, these authors also found that goats favoured the use of personal rather than social information to locate food. Reliance upon personal information may be more important when foraging in a variable or patchy environment.
These studies illustrate how social status affects the use of information when making foraging decisions. However, no work in ruminants has explored the effects of affiliative relationships on the use of social information. In addition, efforts could be made to understand if some personality types utilize or convey social information more than others.

In summary, the social environment influences feeding behaviour in grazing and confined housing systems. Dominant-subordinate and affiliative relationships affect how individuals forage, gain access to feed and adjust feeding patterns when the social environment changes.

\section{Implications for management and animal welfare}

This review has highlighted the wide variability in feeding behaviour among individuals, and how personality differences can explain why some individuals struggle to learn about their feeding environment or fail to adapt to changes in their nutritional, social or physical environment. Our current understanding of the relationship between personality and feeding behaviour remains correlational; we encourage further research to determine causality of these associations. Nonetheless, there is considerable opportunity for farmers to tailor the management of their herd to better fit the needs of these individuals, and thus likely improve their welfare. Using the associations between personality traits and feeding behaviour that have emerged throughout this review we provide suggestions for how changes in management may improve feeding behaviour and intake in farmed ruminants.

In grazing herds, managers can take advantage of foraging strategies where individuals favour searching for new food sources themselves rather than relying upon others. 'Producers' are more likely to widen their grazing distribution and explore new habitats, whereas the more sociable individuals that tend to remain close to herd members are likely to follow the grazing patterns of the 'producers' (Launchbaugh and Howery, 2005). Individuals with exploratory, bold or dominant personalities, or those with strong affiliative or familiar relationships, are known to be especially influential in directing the grazing patterns of the herd. Managers may be able to guide habitat use by cueing or training these individuals where to graze and subsequently may direct the grazing movements of the whole herd through information flow through the group.

In confined systems where the feed bunk is a highly social and often competitive environment, management of these social dynamics should be targeted. Farms that tend to overstock at the feed bunk, or have groups with many highly dominant or aggressive individuals, are likely to see more variable feeding patterns due to individuals adopting different social strategies to gain or maintain access to the feed bunk (e.g. Miranda-de la Lama et al., 2011; Zobel et al., 2011). Consequently, some individuals will be forced to increase their feeding rate, reduce feeding time or access the feed bunk at non-peak feeding times, potentially leading to 
limited or lower-quality feed intake. Managers should aim to provide ample space at the feed bunk and ensure pens have few highly dominant individuals that may monopolize access to the feed bunk; these strategies will help all individuals of the herd to express their preferred feeding patterns.

Farmed ruminants must adjust to stressors such as dietary and environmental transitions, including an introduction to unfamiliar environments like the feedlot or milking parlour, novel foods, or exposure to handling or restraint devices that often occur in conjunction with negative experiences. Negative responses to novelty that potentially impact feeding behaviour could be reduced by, for example, introducing novel diets before movement to a new feeding facility, or by pairing movement through a restraining device with a food reward. This is likely to be especially beneficial for individuals that are most reactive to stressful events. However, it is important to remember that all individuals require time to adapt to change.

Managers should also consider providing an experienced social model, especially when moving animals to new pens requiring the use of different feeding equipment (e.g. headlocks) or when introducing novel feeds (e.g. when artificially weaning young ruminants from milk onto a solid-feed diet). We suggest that individuals that are particularly calm in response to stressors may be effective social models for those that are more reactive, even if they are not knowledgeable or experienced; however, the social model must be familiar to the group to avoid an added stressor.

Some farms already allow for individuals to adapt to transition periods at their own pace. For instance, automated calf feeders have been used to wean calves individually when they reach specific grain consumption targets rather than applying one weaning program to all animals (e.g. de Passillé and Rushen, 2016). Heifers may also be kept in a separate lactating group after calving as they are often of lower social rank and subject to aggression when mixed with the main herd (Neisen et al., 2009). Managing these vulnerable individuals appropriately may improve access to the feed bunk and feeding time (Krohn and Konggaard, 1979).

\section{Conclusions}

This review has illustrated the variability in feeding behaviour of domesticated ruminants and has argued that personality differences can explain why some individuals struggle to learn about, or fail to adapt, to changes in their feeding environment. The propensity of individuals to explore their feeding environment, the reactivity of individuals in response to common management stressors, dominance status and degree of sociability in the herd all affect the ability of individuals to access feed. With a better understanding of how personality influences feeding behaviour, individual management may improve the welfare of individuals, particularly those that have difficulty learning where and what to eat, are typically last to gain access to feed or expend more effort maintaining access to feed.

\section{Acknowledgements}

This review is based on an invited presentation given by MvK at the 10th International Symposium on the Nutrition of Herbivores held in Clermont-Ferrand, France, September 2018. The authors wish to thank Joao H.C. Costa (University of Kentucky) for his helpful input and discussion on topics relevant to this review. M.A.G.v.K. and D.M.W. are supported by Canada's Natural Sciences and Engineering Research Council (NSERC) via the Industrial Research Chair Program with industry contributions from the Dairy Farmers of Canada (Ottawa, ON, Canada), British Columbia Dairy Association (Burnaby, BC Canada), Westgen Endowment Fund (Milner, BC, Canada), Intervet Canada Corporation (Kirkland, QC, Canada), Zoetis (Kirkland, QC, Canada), Novus International Inc. (Oakville, ON, Canada), BC Cattle Industry Development Fund (Kamloops, BC, Canada), Alberta Milk (Edmonton, AB, Canada), Valacta (St. Anne-deBellevue, QC, Canada), and CanWest DHI (Guelph, ON, Canada).

\section{Declaration of interest}

The authors declare no conflict of interest.

\section{Ethics statement}

The present work involved a critical review of existing literature; our institution conducted no study requiring ethics approval specific to this review.

\section{Software and data repository resources None.}

\section{References}

Andrews C, Viviani J, Egan E, Bedford T, Brilot B, Nettle D and Bateson M 2015. Early life adversity increases foraging and information gathering in European starlings, Sturnus vulgaris. Animal Behaviour 109, 123-132.

Arsenos G, Emmans GC and Kyriazakis I 2000. Variation between individuals and the consequences for diet selection by groups of animals. Animal Behaviour 60, 811-820.

Aschwanden J, Gygax L, Wechsler B and Keil NM 2008. Social distances of goats at the feeding rack: influence of the quality of social bonds, rank differences, grouping age and presence of horns. Applied Animal Behaviour Science 114, 116-131.

Baciadonna L, McElligott AG and Briefer EF 2013. Goats favour personal over social information in an experimental foraging task. PeerJ 1, e172.

Barnard CJ and Sibly RM 1981. Producers and scroungers: a general model and its application to captive flocks of house sparrows. Animal Behaviour 29, 543-550.

Barroso FG, Alados CL and Boza J 2000. Social hierarchy in the domestic goat: effect on food habits and production. Applied Animal Behaviour Science 69, 35-53.

Baumont R 1996. Palatability and feeding behaviour in ruminants: a review. Annales de zootechnie 45, 385-400.

Beausoleil NJ, Blache D, Stafford KJ, Mellor DJ and Noble ADL 2012. Selection for temperament in sheep: domain-general and context-specific traits. Applied Animal Behaviour Science 139, 74-85.

Benus RF, Bohus B, Koolhaas JM and van Oortmerssen GA 1991. Heritable variation for aggression as a reflection of individual coping strategies. Experientia 47, 1008-1019.

Bergvall UA, Schäpers A, Kjellander P and Weiss A 2011. Personality and foraging decisions in fallow deer, Dama dama. Animal Behaviour 81, 101-112.

Black TE, Bischoff KM, Mercadante VRG, Marquezini GHL, DiLorenzo N, Chase CC, Coleman SW, Maddock TD and Lamb GC 2013. Relationships among 
Neave, Weary and von Keyserlingk

performance, residual feed intake, and temperament assessed in growing beef heifers and subsequently as 3-year-old, lactating beef cows. Journal of Animal Science 91, 2254-2263.

Boissy A 1995. Fear and fearfulness in animals. The Quarterly Review of Biology 70, 165-191.

Bouissou M, Boissy A, Le Neindre P and Veissier I 2001. The social behaviour of cattle. In Social behavior in farm animals (ed. J Keeling and H Gonyou), pp. 135-147. CABI Publishing, New York, NY.

Burritt EA and Provenza FD 1997. Effect of an unfamiliar location on the consumption of novel and familiar foods by sheep. Applied Animal Behaviour Science 54, 317-325.

Butler D, Holloway L and Bear C 2012. The impact of technological change in dairy farming: robotic milking systems and the changing role of the stockperson. Journal of the Royal Agricultural Society of England 173, 1-6.

Cafe LM, Robinson DL, Ferguson DM, Mcintyre BL, Geesink GH and Greenwood PL 2011. Cattle temperament: persistence of assessments and associations with productivity, efficiency, carcass and meat quality traits. Journal of Animal Science 89, 1452-1465.

Carter AJ, Feeney WE, Marshall HH, Cowlishaw G and Heinsohn R 2013. Animal personality: what are behavioural ecologists measuring? Biological Reviews 88, 465-475.

Chapple RS and Lynch JJ 1986. Behavioural factors modifying acceptance of supplementary foods by sheep. Research and Development in Agriculture 3, 113-120.

Cook NB, Nordlund KV and Oetzel GR 2004. Environmental influences on claw horn lesions associated with laminitis and subacute ruminal acidosis in dairy cows. Journal of Dairy Science 87, E36-E46.

Costa JHC, Adderley NA, Weary DM and von Keyserlingk MAG 2016c. Short communication: effect of diet changes on sorting behavior of weaned dairy calves. Journal of Dairy Science 99, 5635-5639.

Costa JHC, Costa WG, Weary DM, Machado Filho LCP and von Keyserlingk MAG 2016a. Dairy heifers benefit from the presence of an experienced companion when learning how to graze. Journal of Dairy Science 99, 562-568.

Costa JHC, Daros RR, von Keyserlingk MAG and Weary DM 2014. Complex social housing reduces food neophobia in dairy calves. Journal of Dairy Science 97, 7804-7810.

Costa JHC, Meagher RK, von Keyserlingk MAG and Weary DM 2015. Early pair housing increases solid feed intake and weight gains in dairy calves. Journal of Dairy Science 98, 6381-6386.

Costa JHC, von Keyserlingk MAG and Weary DM 2016b. Invited review: effects of group housing of dairy calves on behavior, cognition, performance, and health. Journal of Dairy Science 99, 2453-2467.

Crossley RE, Harlander-Matauschek A and DeVries TJ 2017. Variability in behavior and production among dairy cows fed under differing levels of competition. Journal of Dairy Science 100, 3825-3838.

Crossley R., Harlander-Matauschek A and DeVries T 2018. Mitigation of variability between competitively fed dairy cows through increased feed delivery frequency. Journal of Dairy Science 101, 518-529.

Daniels KJ, Donkin SS, Eicher SD, Pajor EA and Schutz MM 2007. Prepartum milking of heifers influences future production and health. Journal of Dairy Science 90, 2293-2301.

David I, Bouvier F, Ricard E, Ruesche J and Weisbecker JL 2014. Feeding behaviour of artificially reared Romane lambs. Animal 8, 982-990.

Day JEL, Kyriazakis I and Rogers PJ 1998. Food choice and intake: towards a unifying framework of learning and feeding motivation. Nutrition Research Reviews 11, 25-43.

de Passillé AM, Rabeyrin M and Rushen J 2016. Associations between milk intake and activity in the first days of a calf's life and later growth and health. Applied Animal Behaviour Science 175, 2-7.

de Passillé AM and Rushen J 2016. Using automated feeders to wean calves fed large amounts of milk according to their ability to eat solid feed. Journal of Dairy Science 99, 3578-3583.

de Paula Vieira A, von Keyserlingk MAG and Weary D 2010. Effects of pair versus single housing on performance and behavior of dairy calves before and after weaning from milk. Journal of Dairy Science 93, 3079-3085.

DeVries TJ, von Keyserlingk MAG, Weary DM and Beauchemin KA 2003. Measuring the feeding behavior of lactating dairy cows in early to peak lactation. Journal of Dairy Science 86, 3354-3361.
Dingemanse NJ, Kazem AJN, Réale D and Wright J 2010. Behavioural reaction norms: animal personality meets individual plasticity. Trends in Ecology and Evolution 25, 81-89.

Dumont B and Boissy A 2000. Grazing behaviour of sheep in a situation of conflict between feeding and social motivations. Behavioural Processes 49, 131-138.

Dumont B, Boissy A, Achard C, Sibbald AM and Erhard HW 2005. Consistency of animal order in spontaneous group movements allows the measurement of leadership in a group of grazing heifers. Applied Animal Behaviour Science 95, 55-66. Eitam H, Vaya J, Brosh A, Orlov A, Khatib S, Izhaki I and Shabtay A 2010. Differential stress responses among newly received calves: variations in reductant capacity and Hsp gene expression. Cell Stress and Chaperones 15, 865-876.

Enríquez D, Hötzel MJ and Ungerfeld R 2011. Minimising the stress of weaning of beef calves: a review. Acta veterinaria Scandinavica 53, 28.

Escós J, Alados CL and Boza J 1993. Leadership in a domestic goat herd. Applied Animal Behaviour Science 38, 41-47.

Favati A, Leimar O, Løvlie H, Weissing F and Winberg S 2014. Personality predicts social dominance in male domestic fowl. PLoS ONE 9, e103535.

Forbes JM and Kyriazakis I 1995. Food preferences in farm animals: why don't they always choose wisely? Proceedings of the Nutrition Society 54, 429-440.

Forkman B, Boissy A, Meunier-Salaün MC, Canali E and Jones RB 2007. A critical review of fear tests used on cattle, pigs, sheep, poultry and horses. Physiology and Behavior 92, 340-374.

Francisco CL, Resende FD, Benatti JMB, Castilhos AM, Cooke RF and Jorge AM 2015. Impacts of temperament on Nellore cattle: physiological responses, feedlot performance, and carcass characteristics. Journal of Animal Science 93 5419-5429.

Galef BG and Laland KN 2005. Social learning in animals: empirical studies and theoretical models. BioScience 55, 489.

Galindo F and Broom DM 2000. The relationships between social behaviour of dairy cows and the occurrence of lameness in three herds. Research in Veterinary Science $69,75-79$.

Gibbons JM, Lawrence $A B$ and Haskell MJ 2010. Measuring sociability in dairy cows. Applied Animal Behaviour Science 122, 84-91.

Giraldeau LA and Caraco T 2000. Social foraging theory. Princeton University Press, Princeton, NJ, USA.

Goetsch AL, Gipson TA, Askar AR and Puchala R 2010. Invited review: feeding behavior of goats. Journal of Animal Science 88, 361-373.

Greenwood PL, Hunt A., Hermanson JW and Bell A. 1998. Effects of birth weight and postnatal nutrition on neonatal sheep: I. Body growth and composition, and some aspects of energetic efficiency. Journal of Animal Science 76, 2354-2367.

Gutmann AK, Špinka M and Winckler C 2015. Long-term familiarity creates preferred social partners in dairy cows. Applied Animal Behaviour Science 169, $1-8$.

Haskell MJ, Simm G and Turner SP 2014. Genetic selection for temperament traits in dairy and beef cattle. Frontiers in Genetics 5, 368.

Hessle AK 2009. Effects of social learning on foraging behaviour and live weight gain in first-season grazing calves. Applied Animal Behaviour Science 116, 150-155.

Hewitson $L$ 2002. The foraging behaviour of sheep in response to environmental uncertainty. PhD thesis, University of Edinburgh, Edinburgh, Scotland.

Hewitson L, Gordon IJ and Dumont B 2007. Social context affects patch-leaving decisions of sheep in a variable environment. Animal Behaviour 74, 239-246.

Hosseinkhani A, DeVries TJ, Proudfoot KL, Valizadeh R, Veira DM and von Keyserlingk MAG 2008. The effects of feed bunk competition on the feed sorting behavior of close-up dry cows. Journal of Dairy Science 91, 1115-1121.

Hötzel MJ, Longo C, Balcão LF, Cardoso CS and Costa JHC 2014. A survey of management practices that influence performance and welfare of dairy calves reared in Southern Brazil. PLoS ONE 9, e114995.

Huzzey JM, DeVries TJ, Valois P and von Keyserlingk MAG 2006. Stocking density and feed barrier design affect the feeding and social behavior of dairy cattle. Journal of Dairy Science 89, 126-133.

Huzzey JM, Fregonesi JA, von Keyserlingk MAG and Weary DM 2013. Sampling behavior of dairy cattle: effects of variation in dietary energy density on behavior at the feed bunk. Journal of Dairy Science 96, 247-256. 
Jørgensen GHM, Andersen IL and Bøe KE 2007. Feed intake and social interactions in dairy goats - the effects of feeding space and type of roughage. Applied Animal Behaviour Science 107, 239-251.

Khan MA, Bach A, Weary DM and von Keyserlingk MAG 2016. Invited review: transitioning from milk to solid feed in dairy heifers. Journal of Dairy Science 99 , 885-902.

Koolhaas JM, De Boer SF, Buwalda B and Van Reenen K 2007. Individual variation in coping with stress: a multidimensional approach of ultimate and proximate mechanisms. Brain, Behavior and Evolution 70, 218-226.

Koolhaas JM, Korte SM, De Boer SF, Van Der Vegt BJ, Van Reenen CG, Hopster H, De Jong IC, Ruis MAW and Blokhuis HJ 1999. Coping styles in animals: current status in behavior and stress-physiology. Neuroscience and Biobehavioral Reviews 23, 925-935.

Koolhaas JM and Van Reenen CG 2016. Animal behavior and well-being symposium: interaction between coping style/personality, stress, and welfare: relevance for domestic farm animals. Journal of Animal Science 94, 2284-2296.

Krohn CC and Konggaard SP 1979. Effects of isolating first-lactation cows from older cows. Livestock Production Science 6, 137-146.

Kurvers RHJM, Hamblin S and Giraldeau LA 2012. The effect of exploration on the use of producer-scrounger tactics. PLOS ONE 7, e49400.

Kyriazakis I, Tolkamp BJ and Emmans G 1999. Diet selection and animal state: an integrative framework. Proceedings of the Nutrition Society 58, 765-772.

Laland KN 2004. Social learning strategies. Animal Learning \& Behavior 32, 4-14.

Launchbaugh KL and Howery LD 2005. Understanding landscape use patterns of livestock as a consequence of foraging behavior. Rangeland Ecology \& Management 58, 99-108.

Launchbaugh KL, Provenza FD and Werkmeister MJ 1997. Overcoming food neophobia in domestic ruminants through addition of a familiar flavor and repeated exposure to novel foods. Applied Animal Behaviour Science 54, 327-334.

Lensink BJ, Fernandez X, Boivin X, Pradel P, Le Neindre P and Veissier I 2000. The impact of gentle contacts on ease of handling, welfare, and growth of calves and on quality of veal meat. Journal of Animal Science 78, 1219-1226.

Leonardi C and Armentano LE 2003. Effect of quantity, quality, and length of alfalfa hay on selective consumption by dairy cows. Journal of Dairy Science 86, 557-564.

Llonch P, Somarriba M, Duthie CA, Troy S, Roehe R, Rooke J, Haskell MJ and Turner SP 2018. Temperament and dominance relate to feeding behaviour and activity in beef cattle: implications for performance and methane emissions. animal 1-10, doi:10.1017/S1751731118000617

Llonch P, Somarriba M, Duthie C-A, Haskell MJ, Rooke JA, Troy S, Roehe R and Turner SP 2016. Association of temperament and acute stress responsiveness with productivity, feed efficiency, and methane emissions in beef cattle: an observational study. Frontiers in Veterinary Science 3, 1-9.

Loerch SC and Fluharty FL 1999. Physiological changes and digestive capabilities of newly received feedlot cattle. Journal of Animal Science 77.

Løvendahl P and Munksgaard L 2016. An investigation into genetic and phenotypic variation in time budgets and yield of dairy cows. Journal of Dairy Science 99, 408-417.

Lynch JJ, Hinch GN and Adams DB 1992. The behaviour of sheep: biological principles and implications for production. CAB International, Wallingford, UK.

Meagher RK, Weary DM and von Keyserlingk MAG 2017. Some like it varied: individual differences in preference for feed variety in dairy heifers. Applied Animal Behaviour Science 195, 8-14.

Melin M, Wiktorsson $\mathrm{H}$ and Norell L 2005. Analysis of feeding and drinking patterns of dairy cows in two cow traffic situations in automatic milking systems. Journal of Dairy Science 88, 71-85.

Michelena P, Sibbald AM, Erhard HW and McLeod JE 2009. Effects of group size and personality on social foraging: the distribution of sheep across patches. Behavioral Ecology 20, 145-152.

Miller-Cushon EK and DeVries TJ 2011. Effect of early feed type exposure on diet-selection behavior of dairy calves. Journal of Dairy Science 94, 342-350.

Miller-Cushon EK and DeVries TJ 2015. Invited review: development and expression of dairy calf feeding behaviour. Canadian Journal of Animal Science 95, 341-350.

Miller-Cushon EK and DeVries TJ 2016. Effect of social housing on the development of feeding behavior and social feeding preferences of dairy calves. Journal of Dairy Science 99, 1406-1417.
Miller K and Wood-Gush DGM 1991. Some effects of housing on the social behaviour of dairy cows. Animal Production 53, 271-278.

Miranda-de la Lama GC and Mattiello S 2010. The importance of social behaviour for goat welfare in livestock farming. Small Ruminant Research 90, 1-10. Miranda-de la Lama GC, Sepúlveda WS, Montaldo HH, María GA and Galindo F 2011. Social strategies associated with identity profiles in dairy goats. Applied Animal Behaviour Science 134, 48-55.

Nawroth C, von Borell E and Langbein J 2015. 'Goats that stare at men': dwarf goats alter their behaviour in response to human head orientation, but do not spontaneously use head direction as a cue in a food-related context. Animal Cognition 18, 65-73.

Neave HW, Costa JHC, Weary DM and von Keyserlingk MAG 2018. Personality is associated with feeding behavior and performance in dairy calves. Journal of Dairy Science 101, 7437-7449.

Nielsen G 1999. On the interpretation of feeding behaviour measures and the use of feeding rate as an indicator of social constraint. Applied Animal Behaviour Science 63, 79-91.

Neisen G, Wechsler B and Gygax L 2009. Effects of the introduction of single heifers or pairs of heifers into dairy-cow herds on the temporal and spatial associations of heifers and cows. Applied Animal Behaviour Science 119, 127-136.

Nicol CJ 1995. The social transmission of information and behaviour. Applied Animal Behaviour Science 44, 79-98.

Nicol AM and Sharafeldin MA 1975. Observations on the behaviour of singlesuckled calves from birth to 120 days. Proceeding of the New Zealand Society of Animal Production 35, 221-230.

Nkrumah JD, Crews DH, Basarab JA, Price MA, Okine EK, Wang Z, Li C and Moore SS 2007. Genetic and phenotypic relationships of feeding behavior and temperament with performance, feed efficiency, ultrasound, and carcass merit of beef cattle. Journal of Animal Science 85, 2382.

Patison KP, Swain DL, Bishop-Hurley GJ, Pattison P and Robins G 2010. Social companionship versus food: the effect of the presence of familiar and unfamiliar conspecifics on the distance steers travel. Applied Animal Behaviour Science $122,13-20$.

Petherick JC, Holroyd RG, Doogan VJ and Venus BK 2002. Productivity, carcass and meat quality of lot-fed Bos indicus cross steers grouped according to temperament. Australian Journal of Experimental Agriculture 42, 389.

Prins $\mathrm{H}$ 1996. Ecology and behaviour of the African Buffalo: Social inequality and decision making. Chapman \& Hall, London, UK.

Proudfoot $K$ and Habing $G$ 2015. Social stress as a cause of diseases in farm animals: current knowledge and future directions. The Veterinary Journal 206, 15-21.

Provenza FD 1995. Postingestive feedback as an elementary determinant of food preference and intake in ruminants. Journal of Range Management 48, 2-17.

Provenza FD and Balph DF 1987. Diet learning by domestic ruminants: theory, evidence and practical implications. Applied Animal Behaviour Science 18, 211-232.

Provenza FD and Burritt EA 1991. Socially induced diet preference ameliorates conditioned food aversion in lambs. Applied Animal Behaviour Science 31, 229-236.

Provenza FD, Villalba JJ, Dziba LE, Atwood SB and Banner RE 2003. Linking herbivore experience, varied diets, and plant biochemical diversity. Small Ruminant Research 49, 257-274.

Ralphs MH, Graham D and James LF 1994. Social facilitation influences cattle to graze locoweed. Journal of Range Management 47, 123-126.

Ramseyer A, Boissy A, Thierry B and Dumont B 2009. Individual and social determinants of spontaneous group movements in cattle and sheep. Animal 3, 1319-1326.

Rault J-L, Lay DC and Marchant-Forde JN 2011. Castration induced pain in pigs and other livestock. Applied Animal Behaviour Science 135, 214-225.

Raussi S, Niskanen S, Siivonen J, Hã L, Hepola H, Jauhiainen L and Veissier I 2010. The formation of preferential relationships at early age in cattle. Behavioural Processes $84,726-731$.

Reinhardt V and Reinhardt A 1981. Natural sucking performance and age of weaning in zebu cattle (Bos indicus). Journal of Agricultural Science 96, 309-312. Rice M, Jongman EC, Borg S, Butler KL and Hemsworth PH 2016a. Characterisation of Shy-feeding and Feeding lambs in the first week in a feedlot. Applied Animal Behaviour Science 179, 39-45. 
Rice $\mathrm{M}$, Jongman EC, Butler KL and Hemsworth PH 2016b. Relationships between temperament, feeding behaviour, social interactions, and stress in lambs adapting to a feedlot environment. Applied Animal Behaviour Science 183, 42-50.

Rioja-Lang FC, Roberts DJ, Healy SD, Lawrence AB and Haskell MJ 2009. Dairy cows trade-off feed quality with proximity to a dominant individual in Y-maze choice tests. Applied Animal Behaviour Science 117, 159-164.

Rohrer GA, Brown-Brandl T, Rempel LA, Schneider JF and Holl J 2013. Genetic analysis of behavior traits in swine production. Livestock Science 157, 28-37.

Ros-Freixedes R, Sadler LJ, Onteru SK, Smith RM, Young JM, Johnson AK, Lonergan SM, Huff-Lonergan E, Dekkers JCM and Rothschild MF 2014. Relationship between gilt behavior and meat quality using principal component analysis. Meat Science 96, 264-269.

Roth BA, Keil NM, Gygax L and Hillmann E 2009. Influence of weaning method on health status and rumen development in dairy calves. Journal of Dairy Science 92, 645-656.

Rushen J, Taylor AA and de Passillé AM 1999. 'Domestic animals' fear of humans and its effect on their welfare. Applied Animal Behaviour Science 65, 285-303.

Rutter SM 2006. Diet preference for grass and legumes in free-ranging domestic sheep and cattle: current theory and future application. Applied Animal Behaviour Science 97, 17-35.

Sárová R, Spinka M, Arias Panamá JL and Sime Cek P 2010. Graded leadership by dominant animals in a herd of female beef cattle on pasture. Animal Behaviour 79, 1037-1045.

Schwartzkopf-Genswein KS, Atwood S and McAllister TA 2002. Relationships between bunk attendance, intake and performance of steers and heifers on varying feeding regimes. Applied Animal Behaviour Science 76, 179-188.

Sibbald AM, Erhard HW, Hooper RJ, Dumont B and Boissy A 2005. A test for measuring individual variation in how far grazing animals will move away from a social group to feed. Applied Animal Behaviour Science 98, 89-99.

Sibbald AM, Erhard HW, McLeod JE and Hooper RJ 2009. Individual personality and the spatial distribution of groups of grazing animals: an example with sheep. Behavioural Processes 82, 319-326.

Sibbald AM and Hooper RJ 2003. Trade-offs between social behaviour and foraging by sheep in heterogeneous pastures. Behavioural Processes 61, 1-12.

Sibbald AM and Hooper RJ 2004. Sociability and the willingness of individual sheep to move away from their companions in order to graze. Applied Animal Behaviour Science 86, 51-62.

Sih A and Bell AM 2008. Insights for behavioral ecology from behavioral syndromes. Advances in the Study of Behavior 38, 227-281.

Sloan Wilson D, Clark AB, Coleman K and Dearstyne T 1994. Shyness and boldness in humans and other animals. Trends in Ecology \& Evolution 9 , 442-446.

Squires VR and Daws GT 1975. Leadership and dominance relationships in Merino and Border Leicester sheep. Applied Animal. Ethology 1, 263-274.

Stears K, Kerley GIH and Shrader AM 2014. Group-living herbivores weigh up food availability and dominance status when making patch-joining decisions. PLoS ONE 9, e109011.
Thouless CR 1990. Feeding competition between grazing red deer hinds. Animal Behaviour 40, 105-111.

Tolkamp BJ, Kyriazakis I, Oldham JD, Lewis M, Dewhurst RJ and Newbold JR 1998. Diet choice by dairy cows. 2. Selection for metabolizable protein or for ruminally degradable protein? Journal of Dairy Science 81, 2670-2680.

USDA 2014. Dairy 2014. Dairy cattle management practices in the United States. Fort Collins, CO, USA.

Val-Laillet D, Passillé AM de, Rushen J and von Keyserlingk MAG 2008a. The concept of social dominance and the social distribution of feedingrelated displacements between cows. Applied Animal Behaviour Science 111, 158-172.

Val-Laillet D, Veira DM and von Keyserlingk MAG 2008b. Short communication: dominance in free-stall-housed dairy cattle is dependent upon resource. Journal of Dairy Science 91, 3922-3926.

Van Reenen CG, O'Connell NE, Van Der Werf JTN, Korte SM, Hopster H, Jones RB and Blokhuis HJ 2005. Responses of calves to acute stress: individual consistency and relations between behavioral and physiological measures. Physiology and Behavior 85, 557-570.

Van Reenen CG, Van der Werf JTN, Bruckmaier RM, Hopster H, Engel B Noordhuizen JPTM and Blokhuis HJ 2002. Individual differences in behavioral and physiological responsiveness of primiparous dairy cows to machine milking. Journal of Dairy Science 85, 2551-2561.

Vasseur E, Borderas F, Cue RI, Lefebvre D, Pellerin D, Rushen J, Wade KM and de Passillé a M 2010. A survey of dairy calf management practices in Canada that affect animal welfare. Journal of Dairy Science 93, 1307-1315.

Veissier I and Stefanova I 1993. Learning to suckle from an artificial teat within groups of lambs: Influence of a knowledgeable partner. Behavioural Processes $30,75-82$.

Villalba JJ, Catanese F, Provenza FD and Distel RA 2012. Relationships between early experience to dietary diversity, acceptance of novel flavors, and open field behavior in sheep. Physiology and Behavior 105, 181-187.

Villalba JJ, Manteca X and Provenza FD 2009. Relationship between reluctance to eat novel foods and open-field behavior in sheep. Physiology and Behavior 96, 276-281.

von Keyserlingk MA. and Weary DM 2010. Review: Feeding behaviour of dairy cattle: Measures and applications. Canadian Journal of Animal Science 90, 303-309.

Warmington BG and Kirton AH 1990. Genetic and non-genetic influences on growth and carcass traits of goats. Small Ruminant Research 3, 147-165.

Webb LE, Engel B, Berends $H$, van Reenen CG, Gerrits WJJ, de Boer IJM and Bokkers EAM 2014. What do calves choose to eat and how do preferences affect behaviour? Applied Animal Behaviour Science 161, 7-19.

Whalin L, Weary DM and von Keyserlingk MAG 2018. Short communication: pair housing dairy calves in modified calf hutches. Journal of Dairy Science 101, 5428-5433.

Zentall T and Galef B 1988. Social learning: psychological and biological perspectives. Psychology Press, New York, NY, USA.

Zobel G, Schwartzkopf-Genswein KS, Genswein BMA and von Keyserlingk MAG 2011. Impact of agonistic interactions on feeding behaviours when beef heifers are fed in a competitive feeding environment. Livestock Science 137, 1-9. 